\title{
SPONTANEOUS RUPTURE OF THE OESOPHAGUS FOLLOWING ANAESTHESIA
}

M. L. F. Millen, M.D., C.M." and H. B. Grates, M.D., C.M."

FIRST DESCRIBED by Boerhaave in 1724, spontaneous rupture of the oesophagus is a disaster of rare occurrence, and only a few cases have been reported following anaesthesia (1).

A 56-year-old woman was admitted to the Vancouver General Hospital with the complaint of severe difficulty in breathing. Forty-eight hours previously she had had a haemorrhoidectomy performed under general anaesthesia in another hospital. During the post-anaesthetic recovery period the patient had vomited and complamed shortly afterwards of a pain bilaterally over the lower chest which radiated between the shoulders, the pain was aggravated by movement.

Examination on admission revealed a well-developed white female in moderate respiratory distress and showing a slight diffuse cyanosis. The interne noted that she was alert and co-operative. The B.P. was $80 / 40$, respiration 36 per minute; pulse 140 per munute, temperature $100^{\circ} \mathrm{F}$. The only significant physical findings were: (1) some subcutaneous emphysema about the neck, (2) bilateral basal atelectasis.

The patient was seen on the ward by the consulting anaesthetst on -duty, and was intubated under local anaesthesia. A considerable quantity of mucus was aspirated from the trachea. Positive pressure oxygen was administered and under this régime the patient seemed to improve. A chest surgeon was consulted who felt her condition was too poor for surgery though he suspected a ruptured oesophagus. She was taken to the operating room where brenchoscopy was performed under local anaesthesia. This revealed spasm of the lower trachea and swelling of the mucous membrane. Toilet of the lower bronchi removed more mucus.

Following this the patient sat up and coughed up further amounts of mucus; she was sent to the recovery room and maintained on intermittent positive pressure oxygen and neosynephrine-isuprel aerosol.

Her condition remained unchanged and she was returned to the ward the following morning, where during the day she was given A.C.T.H (25 mg.) in 1000 cc. 5 per cent Dextrose in water.

The following day, she deteriorated and became semi-comatose and a repeat bronchoscopic examination was performed; this revealed a lessening of the oedema and very little in the way of secretions.

In the recovery room she was once again placed on intermittent positive pressure oxygen and aerosol.

-Department of Anaesthesia, Vancouver General Hospital, and University of British Columbia. 
She deteriorated during the night; her B.P. fell from $140 / 90$ to $90 / 60$; her pulse became weak and thready and she died at 7:00 A.M. the third day after admission.

Laboratory examinations during admission:

Urinalysis-normal

Total white cell count 12,850

Differential

$$
\begin{array}{rr}
\text { polys } & 40 \% \\
\text { staff } & 46 \% \\
\text { lymphocytes } & 10 \% \\
\text { monocytes } & 4 \%
\end{array}
$$

E.C.G.-Day following admission: suggestive of antero-lateral infarction. Two days following admission: no further evidence to support the possible infarction.

$C$ Chest $X$-rays on the day of admission revealed the following: surgical emphysema in the neck and superior mediastinum; at least two collections of air and fluid in the left side of the chest, presumably in the pleural cavity; a small effusion in the right chast. These were felt to suggest a ruptured oesophagus or bronchopneumonia p.us a ruptured emphysematous bulla. 'The following day the changes were slightly more pronounced.

Post mortem examination revealed the immediate cause of death as pulmonary atelectasis due to mediastinitis from perforation of the oesophagus with contributory empyema and pericarditis. The lesion in the oesophagus was a vertical tear, $1 \mathrm{~cm}$. long, on the left side just above the diaphragm. There was a recent haemorrhoidectomy.

Postoperative emphysema, as was found in this patient ${ }_{2}$ may be due to one of three mechanisms:

1. Rupture of the pharynx or cervical oesophagus due to trauma, for example intubation, gastroscopic examination, etc.

2 Rupture of trachea, bronchus, or bulla.

3. Spontaneous rusture of the oesophagus from mcreased intralummal pressure, for examp_e, vomitıng and conceivable forcmg of anaesthetic gas into the oesophhagus.

This paper will consișder only spontaneous rupture of the oesophagus

\section{INCWENCE}

The incidence of spontaneous rupture of the oesophagus, not associated with trauma, is a rare occurrence, but seems to be increasing in trequency, probably owing to more accurate diagnosis. Cram (2) gives an excellent review of the literature on the topıc. The petients are usually over 40 years of age, though a case has been reported in an infant of 5 months (10). Eighty to eighty-six per cent of cases are males.

\section{ETTOLOGY}

Although there is often a preceding history of alcoholism, ulcer or oesophagitis, rupture may occur in a perfectly healthy individual. It is usually precipitatec by 
vomiting, retching, or defecation especially after a heavy meal. However, vomiting may occur after the severe pain and may be the result of rupture rather than the cause.

\section{Patgogenests}

Ninety per cent of cases occur supra-diaphragmatically and of these, 80 per cent are on the left. Only one case is reported in the literature of perforation in the upper third. This pattern of occurrence has been attributed to several factors by different authors $(2,3,7)$, for at this level: (1) the muscle of the - eesophagus has become smootb; (2) the oesophagus turns to the right; (3) muscle fibres splay out over the cardia of the stomach; (4) the trachea is no longer supporting it; (5) blood vessels and nerves enter; (6) segmental defects are found in the circular muscle layer at the lower end of the oesophagus in some cadavers. Added to this, Anderson (3) reports four cases, all of whom had a lowered plasma protein with a reversal of the A.G. ratio. It has been shown in fresh cadavers (8) that this is the weakest point in the oesophagus-here it will only tolerate 4.5-7.4 (average 5.0 ) lb. pressure. (The child's oesophagus will tolerate twice the pressure and possibly accounts for the lower incidence in the young.) The rapidity of the increase of pressure is probably more important than the actual pressure.

\section{SYMPTOMS AND SigNS (9)}

1. Severe retro-sternal or upper abdominal Jain, often tearing in nature, radiating to the back in the intra-scapular area (a jout T10 level), during or after vomiting.

2. Vomiting most frequently in a male following a heavy meal. The vomitus may show some bright red blood and may disappear after the onset of pain.

3. Rapidly increasing dyspnoea and cyanosis.

4. Signs of shock, though B.P. may remain normal for some time.

5. 50 per cent show surgical emphysema (mediastinal and cervical).

6. Chest signs vary with air and fluid levels.

7. Abdominal rigidity and tenderness have a high incidence especially in the early stages.

8. X-rays show mediastinal emphysema and hydropneumothorax (uni- or bilateral).

9. Thoracentesis may reveal zastric secretions.

Bante considers the triad 0 rapid respiratory rate, rigid abdomen, and subcutaneous emphysema as practically pathognomanic of ruptured oesophagus.

Mackler's (7) triad consists of vomiting, low thoracic pain, and emphysema of the neck.

\section{Differential Diagnosis}

There are many catastropes with which it may be confused; the most frequent are, in order of frequency of mis-diagnosis:

1. Perforated peptic ulcer. In these there is usually, but not necessarily, a history of gastro-intestinal disease; on examinat on there is air subdiaphragmatically which is never seen with a ruptured oesopiagus. Respiratory symptoms and signs are absent. 
2. Eerforated diaphragmatic hernia ulcer. This may be differentiated by fluoroscopy and a Barium swallow. Treatment is the same and it is of little importance to diagnose it.

3. Acute pancreatitis. Pleural effusion may occur, and abdominal pain and shock may be marked. The serum amylase is usually elevated and emphysema does not occur.

4. Coronary thrombosis. This is diagnosed on the basis of known cardiovascular disease, characternstic pain, and E.C A. and fewer, if any, chest signs.

5. Spontaneous mediastinal emphysema.

6. Ruptured bronchus with surgical emphysema. Here there are no gastrointestinal symptoms, the emphysema and pain are severe. Though initially there is no fluid, this may form later.

7. Spontaneous pneumothorax. It may cause the same symptoms, but they are not as severe. Subcutaneous emphysema is rare.

8 Pneumonia or empyaema.

9. Pulmonary infarct or embolus No emphysema occurs; cough and haemoptysis are not seen in rupture of the oesophagus. Abdominal pain and rigidity are less marked if present.

\section{Diagnosis}

This rests on the symptoms and signs, radiological examination revealing emphysema and fluid, Barium swallow showing leak into the mediastinum and pleural cavity, and thoracenthesis aspirating gastric contents.

\section{Treatment}

Some patients will recover with conservative therapy (for example, gastric suction, antibiotics, thoracic drainage, etc.), but since Barrett (4) reported the first case of surgical cure in 1947, this has been considered the treatment of choice. In these, the recovery is $50 \%$.

\section{SUMMARY}

A case report of an unusual sequel to anaesthesia has been presented with a brief review of the literature on spontaneous rupture of the oesophagus

\section{REFERE'NCES}

1. Roy, D W Lancet, 21765 (1911).

2. Cram, R W. C.M A J , 75. 250-253 (1954).

3. ANDErson, R. L. J. Thoracic Surg., 24: 369 (1952).

4. BARRETT, N. Brit. J. Surg., 35: 216 ( 1947).

5. BeAtTIE, J. C M.A.J , 26. 278 (1932).

6. Kinselia, T. J. J. Thoracic Surg., 17: 629 ( 1948).

7. Barfett, N. Thorax, 148 (1946).

8. Macklen, S A. Surg, Gynec. \& Obst, 95.345 (1952).

9. WARE, G. W. Arch. Surg, 65: 723 (] 952).

10 Menne, F R \& Moore, C. U. Spontaneous Rupture of the Oesophagus in an Infant. Arch Pediat., 38: 672 (1921).

11 Strong, G F., Wirson, R \& TAylor, H. C M.A.J , $65: 455$ (1951). 